\title{
Women, Displacement and Exclusion: Narratives of Women Affected by Development-Induced Displacement
}

\author{
Hemalatha $\mathrm{K}^{*}$
}

\begin{abstract}
Development Induced displacements are usually accompanied by a 'downward spiral of impoverishments'. They result in widespread psychological and socio-cultural impacts. The worst hits are women and children who are counted among the marginalised segments in these situations. The present paper brings out the narratives of five women displaced during the building of a dam at Almatti in Bagalkot district of northern Karnataka. The thematic analysis reflects the theoretical formulations of risks to which displaced people are exposed and the narratives bring out the deterioration of their living conditions.
\end{abstract}

Keywords: Development Induced displacements, Psychological and Socio-cultural Impact, Bagalkot Dam, Upper Krishna Project

\section{Introduction}

Women are often enumerated with their children to make up for nearly 70 percent of the total internally displaced population in man sites in India. Most of this segment has suffered immensely due to forced displacement. Ghimire (2011) observes that the brunt of the changed reality after displacement is felt by women. It makes the woman's role as a caregiver more difficult. It also results in women facing a backlash from the male members' frustrations as they are unable to fulfill the family's needs. Development Induced displacements are usually accompanied by a 'downward spiral of

* Department of Sociology and Social work, CHRIST (Deemed to be University), Bangalore, India; hemalata.k@christuniversity.in 
impoverishments'. They lead to widespread psychological and socio-cultural impacts which are traumatic for the displaced people. Researchers have reported dehumanising and disempowering consequences on a large scale to the population.

Women have a critical role in situations of forced migrations as they are the users as well as conservers of available resources. Their contribution to sustainable development is known (UNFPA, 2012). Gender relations are strongly affected by the contexts in which they are studied. Hans (2008) describes displacement as a gendered process where the experiences of women are different from that of men. The changed circumstances within the context of their traditional roles cannot be wholly applied. Women may be forced to play dual and challenging roles of homemaker and breadwinner.

United Nations High Commission for Refugees (UNHCR) acknowledges that forced as well as planned relocation can have negative effects on women due to intense changes. The disempowering situations which impact women are multidimensional. Their role of being responsible for children and the aged within their families become more crucial. The isolations created by newer circumstances make women more vulnerable especially due to the exclusion from decision-making processes which results in a voiceless existence of being unable to share opinions and ideas. They are unable to regain any control over the environment. Their negotiations with the outer world are only through the male members. In these circumstances a women's ability to participate effectively in the processes related to displacement becomes difficult. For instance, attending meetings called by the authorities post displacement or to take part in the capacity building activities becomes difficult resulting in poor choices of livelihood (UNHCR, 2008).

The dual negative impact felt by women due to male biases were reported by Mehta (2002). Firstly, patriarchal societies perpetuate unequal access to resources. Besides this, the structural processes are also biased towards males as seen in policies and regulations. Women are marginalized during and after displacement and rehabilitation because they are governed by new authorities in rehabilitation sites and are economically dependent on the 
measures taken by these authorities, all of which 'contributes to women's sense of powerlessness'.

\section{The locale of the Study}

Construction of two major dams at Narayanpur and Almatti in the 1960s to irrigate drought-prone area of northern Karnataka came to be called as the Upper Krishna Project. Of the two dams, Narayanpur dam was constructed in a relatively flat, broad valley situated about $60 \mathrm{~km}$ downstream from Almatti dam. Partidge asserts that "these two reservoirs are interlinked and together displaced about three lakh people excluding those displaced by canals and other irrigation structures, by far the largest displacement ever caused by any project in India" (Partidge, 1985, as cited in Parasuraman, 1993).

All the relief and rehabilitation work was undertaken through government resolutions (GRs). Broadly, the GRs had the following elements: payment of cash compensation for lands and houses acquired; provision of house plot to those who lost their homes and assistance in shifting people to the relocation sites; and creation of a civic infrastructure in the relocations sites (GOK 1990, as cited in Parasuraman, 1993)

Guiding Principles on Internal Displacement (1997) elucidates the impact of displacement on people as the process which results in broken families. It brings to an end traditional livelihoods, disrupts opportunities that were previously available. The access to food, medicine and shelter is minimised and in cases completely nonexistent.

\section{Displacement and Exclusion}

Although all persons affected by human rights violations suffer, displacement from one's place of residence makes the internally displaced particularly vulnerable and excluded from the positive impact of development projects. The following are some of the factors that are likely to increase the need for protection (UNHCR, 2004): 
- "Internally displaced persons may (i) be in transit from one place to another, (ii) be in hiding, (iii) be forced toward unhealthy or inhospitable environments, or (iv) face other circumstances that make them especially vulnerable. In the process, women are known to suffer from discrimination, rape and abuse, among others;"

- "The social organisation of displaced communities may have been destroyed or damaged by the act of physical displacement; family groups may be separated or disrupted; women may be forced to assume non-traditional roles or face particular vulnerabilities;"

- "Internally displaced populations, and especially groups like children, the elderly, or pregnant women, may experience profound psychosocial distress related to displacement;"

- "Removal from sources of income and livelihood may add to physical and psychosocial vulnerability of displaced people, including women;"

- "Schooling for children and adolescents may be disrupted, but when this happens, women are forced into giving home lessons to their children in the interim;"

- "Internal displacement to areas which are inhospitable, or where local inhabitants are of different groups, may increase risk to internally displaced communities; internally displaced persons may face language barriers during displacement;"

- "Internally displaced persons may lack identity documents essential to receiving benefits or legal recognition; in some cases, fearing persecution, displaced persons have sometimes disposed of such documents."

\section{Theoretical Backdrop for the Study}

This study is based on a theoretical model proposed by Michael Cernea, an anthropologist who worked for the World Bank on policy matters from 1974 to 1997 . He called it the 'Impoverishment 
Risks and Reconstruction Model' which could mitigate the risks of displacement. The risks identified by Cernea include: (a) Landlessness; (b) Joblessness; (c) Homelessness; (d) Marginalization; (e) Food insecurity; (f) Increased morbidity; (g) Loss of access to common property resources; and (h) Community disarticulation. It should also be noted in spite of having nearly two crore people affected by displacement, the Indian States do not have a satisfactory rehabilitation plan or policy (Fernandes, 1991).

The theoretical model specifies the risk reversal processes that can be adopted for dealing with each of these risks. Cernea (1997) delineates four vital functions that this model can perform viz. predictive function, diagnostic function, problem-solving function and the research function. The present study used this model to have apriori knowledge of the vulnerabilities leading to social and personal exclusions experienced by the five participants.

\section{Research Methodology}

The study with the objective of bringing out experiences of women who were displaced requires a qualitative approach. An in-depth exploration of human phenomena, projecting the world-views of those women and the complexity and contexts of their lived experiences can be effectively presented with a qualitative exploration. In-depth interviews or "guided conversations" as described by Gubrium and Holstein, 2002 are best suited to elicit experiences as well as understand the meanings that participants attribute to the phenomena of displacement.

The present paper is based on in-depth interviews with five women. The researchers were able to establish a high degree of rapport and were able to reciprocate to the participants' observations to bring out their perspectives on displacement. They were able to create contextual knowledge and this paper appropriately projects the rich descriptions given by the participants.

As identifying and refining important concepts is a key part of the iterative process of qualitative research, the theoretical model proposed by Michael Cernea formed the backdrop for the interviews. Similar themes emerged during the analysis of the 
factors underlying the exclusion felt by the participants. The process of creating codes was thus predetermined. This is often referred to as deductive or "a priori". The predetermined coding was thus based on key concepts in the theoretical construction of Cernea. This led to deductive thematic analysis as a predetermined framework to analyse data. As most of the coding schemes were based on the theoretical framework of Cernea's model, the researchers used this theory to analyse the data.

\section{Profile of the Research Participants}

The women who participated in the present study came from varying backgrounds though all of them lived in Bagalkot town. There was no similarity in their forced displacement experience, but rather a multiplicity of circumstances and consequences. The participants of the study were from the rehabilitation centres closer to Bagalkot town. The oldest member was sixty-year-old Hindu whose husband died four years earlier. She has no children and cannot remember which year she moved to the present location. She can recall that she originally came from old Bagalkot. Similarly, the second participant was a forty-five year old woman who also moved from old Bagalkot twelve years ago. She moved initially to the temporary shelters that the government had erected. She moved to the present location around 12 years ago. She has four sons but her husband died a couple of years ago. Another participant was fifty-five years old, who moved from old Bagalkot. She lost both her husband and daughter later. The fourth participant is fifty-five years old and she also moved from old Bagalkot. She had lived with her husband for three years before he died. She has three children who are now grown up. She moved to the present location in 2004 from a village called Hale Pete. The only Muslim participant was forty years old without children and her husband had abandoned her. She came to the present location in the year 2000 from a village called Haveli. These women were purposely chosen as all were old enough to have been part of the displacement experience. They were all middle-aged some being either deserted or widowed.

It was noted from the larger field survey conducted by the author that women are not a homogenous category. In situations of 
displacement, their vulnerability is dependent on certain socially significant attributes such as age, religion, education, the presence of male members in their lives and the capacity to own assets. The attributes like religion can also play a role in managing their vulnerabilities. It was found during field studies in West Bengal, the deserted and widowed women among the Muslim community get a lot of support from certain practices like Fetura, Zakhat and Asul, prevalent among the Muslims, which define the imperative of helping the poor ( $\mathrm{O}^{\prime}$ Neill, 2010). This, of course, is not the case with other religious groups. Some members of the present sample are widowed or deserted but the traditional support is not noted in any of them. Even the single Muslim participant only stated that the mosque helped her in getting a divorce but it is her parental family that was supporting her.

\section{Articulating the Themes from Analysis}

\subsection{The trauma of displacement}

The major articulation of these women in their discussion about displacement was about the immediate trauma of being thrown out of their homes. As reported by most other researchers of population displacement, this has created a lasting memory which they describe as being the single most unforgettable experience in their lives. More than a decade has passed since the initial occurrence of displacement but the research participants are deeply moved by its impact on their lives. A participant notes,

"We were told that the water would come. They (Government officials) came, they told us to move, put up sheds for us. We didn't take it seriously. We thought it is not going to happen now, and by the time we had time to react, the water came in unexpectedly. We were watching when the water gushed in. The gutter in front of the house filled in no time and suddenly I was standing in hip-deep water".

It has been stated in some studies that women do not participate in any of the community meetings to be aware of or being pre-warned of displacement. They lived by what they heard from others, but they knew vaguely that something may happen. The real event thus had left them highly traumatised. A participant reminisces, 
"So much of our things were left behind, so many losses. Plots were given to build houses but nobody had moved to the new place, we were all wondering how to live alone in the new place. It was like everyone waited for everyone else and in no time water filled our houses."

The repeated observations of all the participants were the deep sorrow they experienced. A responder notes,

"When the tractors finally came to take us, we were in pain (sobs). Leaving our homes was difficult. But we were allowed to take our valuables with us".

The immediate reaction to the event was repeatedly mentioned by the participants. A participant asserts,

"When the men folk drank liquor, we women would get together and be away from them. We spoke about the times we had to leave. Then it was all pain and fright. While leaving the village, it felt suffocating."

The women state that they were neither aware fully of the Relief \& Rehabilitation benefits provided by the project authorities, nor were they consulted by their family about the decisions related to purchasing of land and purchase or construction of houses. Exclusion of women in all discussions is a normal practice reported from different displacement sites. Women are systematically ignored in the resettlement process by the government in terms of both providing facilities as well as in developing gender-sensitive rehabilitation policies. The government fails to recognise that a considerable proportion of the displaced population is women and hence there is a need for gender-sensitive rehabilitation policies.

\subsection{Loss of Land, Homes and Livelihoods}

Re-establishing a viable economic and social role in the new settings (the newly constructed town of Navnagar) completely removed the women from their previous lives which were predominantly agrarian with strong social networks. The economic isolation of female displaced persons was most noticeable when they were rehabilitated in urban areas. A participant recollects,

"Here in the town, there were no suitable jobs for us. In our village, we were agricultural labourers, and that was good for us. 
But here in the city, I couldn't do domestic work. Going to people's houses and cleaning was not something I wanted to do. Both my mother and I get four hundred rupees each month. We strive to manage in that much, but everything being expensive, we have to resort to other means".

Displacement impacts the economic wellbeing of households. Although a problem for all, women are at a unique disadvantage: In these situations, they are forced to cut off their previous livelihoods related to agriculture and allied occupations. They lose their strong social networks and find it difficult to adapt to new social and economic roles. Majidi and Hennion (2014) noted that economic isolation becomes pronounced when they relocate to urban areas. The male-dominated workplaces of urban centres intimidate displaced women. An increase in unemployment and loss of women's access to viable livelihoods and economic independence is generally noticed. Similar sentiments were expressed by the participants of the present study.

The participant who belonged to a family of weavers was forced into an unstable livelihood. A participant notes,

"Business suffered when we moved here. Getting a loan and a structure ready to start weaving and earning money, took us a long time. The delay also affected loan repayment. It took us almost three years to settle everything. It was the most difficult time. We borrowed from other people, for we did not have anything to eat also. We worked as labourers in other handloom mills, for our expenses. Even now, if we work, we will have something to eat, otherwise nothing"

Fernandes and Raj (1992), note that in situations of job scarcity, women would always be the first to lose their jobs. This is in some way understandable as women in the present study were found to have no skills to function within the job market. In India till the late 80 s rehabilitation scheme followed the norm of one job provided for each family which was displaced and it was inevitable for the male members to get this job. Fernandes and Raj (1992) also observed this in the rehabilitation process following the construction of the National Aluminium Company. 
South Asian studies on displacement speak of the population lacking viable skills to participate in the labour market which makes displaced women unable to participate in the urban employment arena. In a study on displacement in Afghanistan, women show "a strikingly high level of illiteracy, even by Afghan standards, with 97.6 per cent of women were found to be completely illiterate, against a national rate of illiteracy of 88 per cent" (Majidi and Hennion, 2014). Literacy is considered one of the most basic skills necessary to enter an urban labour market dominated by services. Lack of basic literacy is an important indication that women are poorly equipped to adapt to urban markets which they have to enter post displacement.

This economic exclusion hits hardest women who are widowed. In the larger field survey undertaken by the author, widows made up a part of the total female participants. Their situation becomes, in this context, more poignant. The limited employment opportunities are an immediate concern for widows and female head of households. Widows reported the lowest income during displacement in several studies. 71 per cent earned only 588 Afghanis (\$12) a month (53 per cent below the poverty line) in the study from Afghanistan (Majidi and Hennion, 2014). All these flaws of the informal sectors are evident in the words expressed by the research participants.

\subsection{Changed lifestyles}

All the miseries attached to overcrowded dwelling spaces were reported by the participants. Especially those related to sanitation facilities impacted women more than men. The exclusion that women face in finding basic living facilities is explicit in their words. Violence against women gets augmented by lack of space and living in cramped tents and temporary accommodation. Furthermore, the change in traditional housing conditions, especially from rural to the urban environment, means that women see their freedom of movement greatly constrained, as they cannot benefit from the relative protection of their own communities found previously. It has been found that the imposition that comes with co-existence with other communities, something unheard of in 
their native villages, relegates women to narrower confines of their homes. This also aggravates their situation.

Displaced women are more likely to be socially isolated and lack traditional protective mechanisms. Analysis of qualitative data revealed that displaced women and girls increased economic vulnerabilities not only place them at a higher risk of, for instance, prostitution and forced marriages, but also typically leave them without the resources to seek assistance.

An instance came from a participant who faintly brushed over the issue of Devadasis but refused to further clarify details. She says,

"After coming here, Mutt Kataskond idini (social license of devotional prostitution) with Goddess Yellamma. While in Bagalkot I was a Soubhagyavathi. I pray to her and go to that temple once a year."

This statement confirms the move from Old Bagalkot to Navanagar, forced her to receive the Muttu which is the most often used terminology for the acceptance of becoming a Devadasi. This was due to her financial condition compounded with the need for male protection after the death of her husband. Either way, when the displacement is pushing women to such situations, it is an alarming call for our system to make policies that aim at protecting the right of women over their own lives.

\subsection{Deprivation}

After displacement, land and forests which were sources of nutrition and work (additional income) outside their house were completely lost. This deprivation following displacement is compounded with the absence of productive employment in the resettlement area. Women are, forced to remain at home and only look after the household, without any productive work outside. (Fernandes, 1996).

Modi (2004) speaking of the situation around the Sardar Sarovar Project observes that women were dislodged from their ancestral lands and from a fairly self-sufficient life. A number of inadequacies become part of their life. It was found that the caloric intake of women had fallen. A responder analyses the situation and says, 
"Vegetables are forty a kilo, even if I buy a quarter kilo, it is ten rupees. With children and youngsters, a quarter kilo is never sufficient, so I need to buy half a kilo. When everything becomes very expensive we eat little-little and wait for days to pass."

Due to a reduced supply of food crops and their prices, everincreasing women are not able to find sustenance which was possible when they had access to agricultural produce. To include increased costs and additional expenses family budget were readjusted and expenses on food were reduced. Women and female children were the first victims of the allocation of money for food.

\subsection{Loss of Common Property Resources}

Common property resources are those that are held by the community as a whole. These are best exemplified by access to common land, forest, river, sea, fisheries, cattle, grazing land. All of these support subsistence livelihoods and provide greater security against the risk of poverty to women in particular. Additionally, women have the responsibility of collecting fuel, wood, fodder, and minor forest produce and water for their family. One of the participants says,

"....there our firewood was easily available, but here we pay five hundred sometimes six hundred to buy wood. When we came here as refugees, everywhere it was poverty. Earlier, we could live with fifty rupees a day, here all that is not possible".

Women lose their rights over these resources. This is seldom focussed upon when planning for rehabilitation of the displaced. These resources are often not replaced during resettlement with women often bearing a disproportionate share of the resulting costs.

\subsection{Family Disintegration}

Unavoidable disintegration of joint families under the impact of forced relocations was reported by Ganguli, (2014). Generally, a joint family structure presents a well-knit system where there are general norms binding the members of the family. Women in this type of family structure occupied a unique position. In many traditional families, an old widowed mother or the wife of the main 
earning member of the family held the most privileged position and she generally had the right to control each and every decision within the family. In the present study, no such consideration and support are found.

"My in-laws received compensation. They got land to build houses, money and what not. But they took all that. And because I had no children, I had no share. As the property was on their name, they got compensation and took everything. My motherin-law said to me, 'why should I give you anything? You don't have children, you are alone. Go to your tavaru mane (mother's house). You have nothing here and sent me away."

When women have a property in their names the story is slightly different experience:

".....after the death of my husband, my brothers brought me back home and built a shed for me. As the shed was on my name, I got this plot here (Navanagar). Between five siblings we got rupees 40,000. How do we build a house with that much? Now the shed expense itself is more than that."

\subsection{Social Disintegration}

Women often also find it difficult to maintain relationships with friends and neighbours who were known from generations together. One of the member's said,

"When someone is getting married or someone has died, we don't know, and cannot even go to see them. That is why; we take a tum-tum (auto rickshaw) go around the whole town and pick up people from the family and the caste, and take them to the house where the death or occasion is taking place. Illa andre yaaru nodavaru irolla (otherwise, there will be nobody to see off the dead). This is all because we are far away now. Before, we were all in the same area, like a colony. We could walk to the other houses."

Though newer practices were observed to hold people together, a steep fall in social integration is observed.

\subsection{Resilience}


Any study focusing on exclusion will bring out features that help these women survive. The resilience exhibited by these women in facing such extreme change in their circumstances was worth reporting. An analysis of the exclusionary processes makes it necessary to project the mental makeup of women to face life. Resilience requires re-building lives and livelihoods. To encourage survival and promote the resilience of displaced women, and ultimately of their households, the first step needs to be economic capacity building and vocational training. Our research shows that women bear unfavourable economic conditions after displacement and hence their household's livelihoods suffer from their inability to contribute to the household income, creating tensions and leading to untold suffering.

The most positive sign of resilience noted by the author was in one case where the woman is using the mode of self-help groups very positively. She said,

"I am a part of many Groups (Self Help Groups). I took from that Group and this Group (multiple memberships) and managed expenses. I am a part of three groups. I use most of it for my Banana business. Put it into buying the fruit and once the profit comes, pay back the group."

Most others resort to faith and religious rituals as sources of solace and emotional succour. In fact, most of the participants speak about this repeatedly.

"Seva (service) for goddess yellamma has to be done twice a week. At least five houses I have to visit. She takes care of me. The dakshina (fees) I get because of her has saved me from going hungry many times. Yellamma is in the family. Earlier my sisterin-law would practice it and after her death, I took over. It is been about fifteen years since I have started worshipping goddess yellamma."

The words articulate the strengths, resilience and coping strategies of these women. In spite of being inundated with bitter experiences which still traumatise them, they continue to survive in the resettlement areas. 


\section{Conclusion}

Most researchers, as well as administrators, state that development projects by themselves are not disastrous unless there are vulnerable populations who do not have the capacity to absorb it and who are unable to cope with it. It is also the social, cultural, economic and political environment that has abetted the exclusion that women face due to disaster and displacement. In the present study, the researchers bring in gender as an attribute which highlights the negative impact of displacement. It was also been found that though this kind of disaster and the subsequent displacement of a human population affects both men and women, it is women who have suffered more.

Women have been seen as being especially vulnerable in most contexts of human existence. The author undertook the quantitative study looking at the population as being uniform in their experience as victims of the development induced displacement process. During the research process, we realised that women had to be looked with a different approach. This inspired this qualitative approach to the study as well for this paper to be written. Social workers have started to believe that all policy decisions and implementation processes should include all vulnerable populations including women.

\section{References}

Cernea, M. M: (1997) The Risks and Reconstruction Model for Resettling Displaced Populations, World Development, 25(10), October, Pergamon Publication, Great Britain.

Chully. A., \& Hemalatha, K. (2017). Development induced displacement: Population displacement and mitigation in Bagalkot district. Center for Publications, CHRIST (Deemed to be University), Bengaluru.

Fernandes, W. (1991). Power and powerless: development projects and displacement of tribals. Social Action, 41(III), 243-70.

Fernandes, W. (1996). India's forced displacement policies and practicesis compensation up to its function. Retrieved from onlineministries.creighton.edu.

Fernandes, W., \& Anthony Raj, S. (1992). Development, displacement and rehabilitation in the tribal areas of Orissa. Indian Social Institute, New Delhi 
Ganguli, N. (2014). Refugee Women in Calcutta (1947-1958). Journal of Internal Displacement, 4(1), 12-27.

Ghimire, A. (2011). Rethinking "women" in forced displacement. Refugee Watch, 3, 30-43.

Gubrium, J. F., \& Holstein, J. A. (2001). Handbook of interview research: Context and method. Sage Publications.

Guiding Principles of Internal Displacement: (2004). retrived from https://www.unhcr.org/protection/idps/43ce1cff2/guidingprinciples-internal-displacement.html, New York: United Nations, UNHCR.

Hans, A. (2008). Gender, Camps and International Norms. Refugee Watch, $32,64-73$.

Majidi, N., \& Hennion, C. (2014). Resilience in displacement. Journal of Internal Displacement, 4(1), 78-91.

Mehta, L. (2002, September). The double bind: A gender analysis of forced displacement and resettlement. In Conference Paper presented at Conference on Engendering Resettlement and Rehabilitation Policies, India, New Delhi (pp. 12-13).

Modi, R: (2004) Sardar Sarovar Oustees: Coping with Displacement. Economic and Political Weekly, 13, 1123-1126.

O'Neil, (2010). Women and Displacement: A Case Study of Women displaced by Ganga erosion in Malda district of West Bengal in India, Development and Environment: retrived from epc2010.princeton.edu/papers/100534.

Parasuraman, S. (1993). Impact of Displacement by development projects on women in India. Working Paper Series No. 159, Institute of Social Studies, The Hague.

UNFPA Annual Report. (2012). Retrieved from www.unfpa.org/ publications/adding-it-2012 